\title{
Cystic prostatic carcinoma: case report and literature review
}

KH Fung ${ }^{1}$ *, MB, ChB, WK Tsang ${ }^{1}$, MB, ChB, Philip CH Kwok ${ }^{1}$, MB, BS, WT Lee², MB, ChB, KW Tang ${ }^{1}$, MB, BS

${ }^{1}$ Department of Radiology and Imaging, Queen Elizabeth Hospital, Jordan, Hong Kong

${ }^{2}$ Department of Pathology, Queen Elizabeth Hospital, Jordan, Hong Kong

* Corresponding author: alexjordanfung@yahoo.com

Hong Kong Med J 2020;26:66-9

https://doi.org/10.12809/hkmj197984

\section{Case report}

In April 2017, an 81-year-old man presented to the emergency department with acute urinary retention. Digital rectal examination revealed a grossly enlarged prostate with a hard nodule felt at the left lobe. The patient was subsequently catheterised and haematuria with a small number of blood clots was noted. Urine cytology and microbiology were negative. Prostate-specific antigen (PSA) was elevated at $23.8 \mathrm{ng} / \mathrm{mL}$.

Cystoscopy revealed a trabeculated urinary bladder with multiple small bladder diverticula but no mucosal lesion and a grossly enlarged prostate. The patient was prescribed terazosin and successfully weaned off the Foley catheter. However, the patient required repeat admissions for recurrent acute urinary retention. He was managed with an increased dose of terazosin and intermittent selfcatheterisation.

Computed tomography (CT) urogram was performed as part of the haematuria examination and revealed an approximately $10-\mathrm{cm}$ hypodense cystic lesion in the rectovesical space. No preserved fat plane was present between the lesion and seminal vesicles and prostate, or the lesion and rectum. Internal enhancing solid components were seen in the left posterior aspect of the mass (Fig a and b).

On magnetic resonance imaging (MRI), the mass was again noted between the rectum and the prostate. The mass showed predominantly T1-weighted hyperintense signal which could represent proteinaceous or blood product. In T2weighted sequence, the mass was heterogeneously hyperintense. A solid component previously detected on $\mathrm{CT}$ scan demonstrated $\mathrm{T} 1$ - and $\mathrm{T} 2$ weighted intermediate signal intensity, with restricted diffusion and contrast enhancement. (Fig c to g) The differential diagnoses included a seminal vesicle or prostatic tumour, a rectal tumour such as gastrointestinal stromal tumour, or a neuroendocrine tumour.

A CT-guided biopsy was performed for histology. The centre of the mass was first biopsied and yielded old blood products. Cytology revealed necrotic cells and blood cells but no tumour cells.
Because of the high suspicion of underlying malignancy, biopsy was repeated under contrast CT guidance. The solid component on the left side of the cystic mass was biopsied and yielded friable soft tissue. Pathology examination revealed tumour cells that comprised closely packed, back-to-back and cribriform glands, lined with a single layer of neoplastic cells with amphophilic cytoplasm, enlarged, roundish nuclei, fine chromatin, and prominent eosinophilic nuclei. It showed no ductal component. Immunohistochemically, the cells were positively stained with PSA and also showed strong and diffuse expression of NKX3.1 (a prostatic marker) but were negative for synaptophysin (a neuroendocrine marker). The overall features were of acinar-type prostatic adenocarcinoma with a combined Gleason score of $8(4+4)$.

Positron emission tomography with $68 \mathrm{Ga}$ PSMA tracer was performed for disease staging. Increased 68Ga-PSMA uptake was present in the left prostate lobe spanning from the apex to the base together with a right prostate apex peripheral zone lesion. Multiple 68Ga-PSMA-avid lesions were seen scattered in the cystic mass, in keeping with carcinoma of the prostate. Mildly 68Ga-PSMAavid lymph nodes were seen at the retrocaval and bilateral posterior triangles, suspicious of nodal metastases. The patient was treated as disease with nodal metastasis. Luteinising-hormone releasing hormone analogue with androgen blockage was commenced as palliative hormonal therapy. The pretreatment PSA in August 2018 was $30.7 \mathrm{ng} / \mathrm{mL}$ but had decreased to $0.3 \mathrm{ng} / \mathrm{mL}$ in February 2019. At follow-up examination, the patient was able to void well and terazosin was discontinued.

\section{Discussion}

A giant cystic mass in the male pelvis is not common. ${ }^{1}$ In this case, an elevated PSA could suggest that the cystic pelvic mass was prostatic in origin. ${ }^{2}$ Most prostatic cystic lesions are benign and malignant prostatic cysts are very rare. ${ }^{3}$

Prostatic cysts can be congenital or acquired. Congenital cysts are associated with an abnormality in the paramesonephric (Müllerian) duct or 

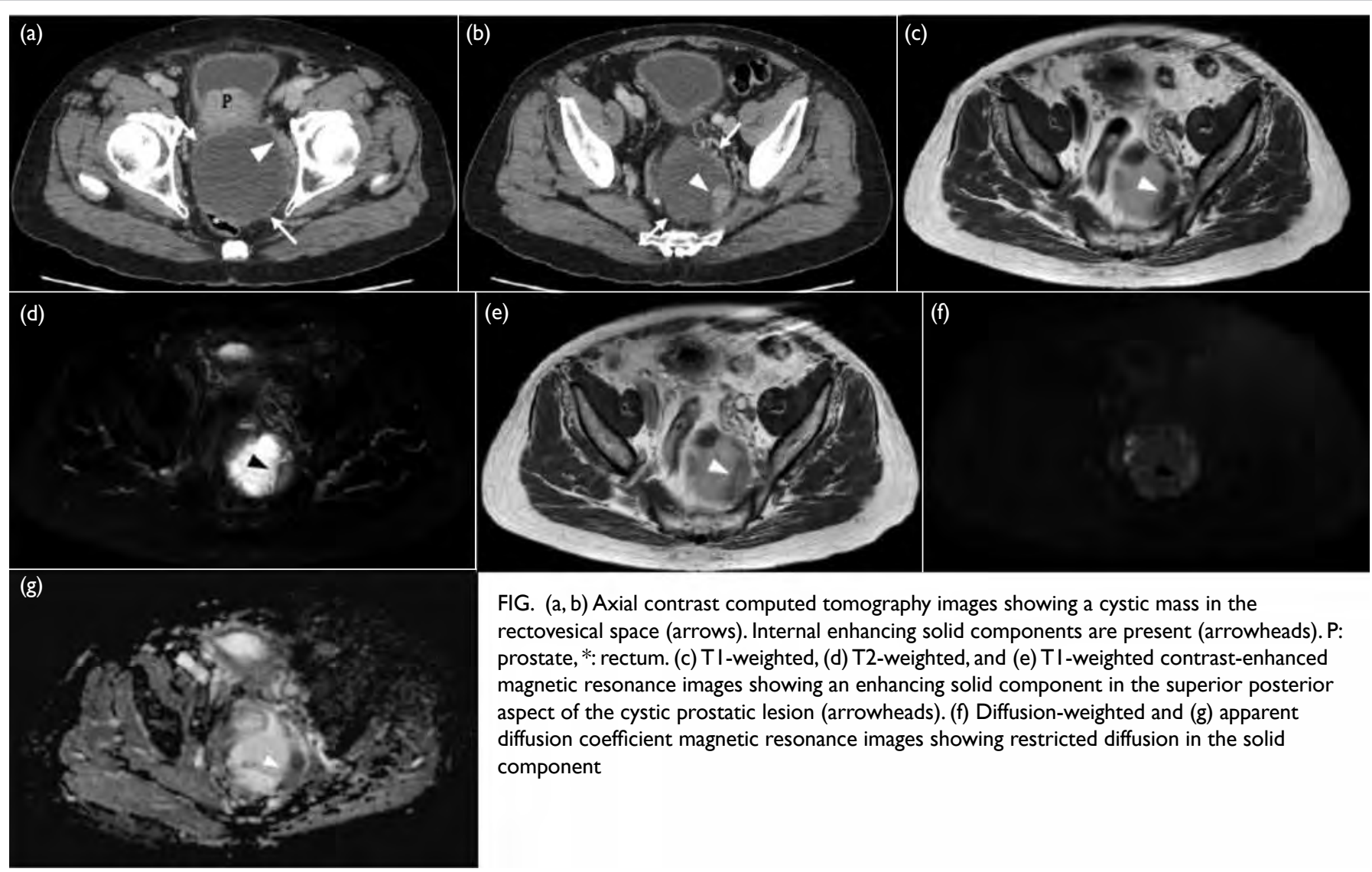

FIG. (a, b) Axial contrast computed tomography images showing a cystic mass in the rectovesical space (arrows). Internal enhancing solid components are present (arrowheads). P: prostate, *: rectum. (c) TI-weighted, (d) T2-weighted, and (e) TI-weighted contrast-enhanced magnetic resonance images showing an enhancing solid component in the superior posterior aspect of the cystic prostatic lesion (arrowheads). (f) Diffusion-weighted and (g) apparent diffusion coefficient magnetic resonance images showing restricted diffusion in the solid component

mesonephric (Wolffian) duct. Acquired cysts are usually benign and may include retention cysts or prostatic abscess. ${ }^{4}$

Malignant prostatic cysts include papillary cystadenocarcinoma, combined transitional cell/ adenocarcinoma, and cystic prostatic carcinoma. ${ }^{4}$ Prostatic carcinoma presenting as cystic lesions rather than solid lesions is uncommon. Rarely, leiomyoma or liposarcoma in the prostate may have cystic elements. ${ }^{4}$

A literature search on cystic prostatic carcinoma and cyst associated with carcinoma of prostate revealed nine case reports with histologically proven cystic prostatic carcinoma between 1991 and 2016 (Table 1). ${ }^{2,5-12}$ Case reports without full text available and those written in languages other than English were not reviewed.

The clinical findings of our case were similar to those of the other nine reported cases. Cystic prostatic carcinoma usually affects older adults. Patients usually present with mass effect of the prostatic cystic tumour. The size of prostatic cystic tumour is usually large, on average $6.8 \mathrm{~cm}$ in this case series (Table 1). The most common presenting symptoms were lower urinary tract symptoms and acute urinary retention. In this case series, PSA was often very high, on average $243.2 \mathrm{ng} / \mathrm{mL}$ (Table 2 ).
Clinicians and radiologists should be aware of this disease entity as a differential diagnosis of large cystic mass in the male pelvis. Cystic prostatic carcinoma has been reported with typical imaging features. Imaging findings in our case were consistent with those of other reported cases. On ultrasound or CT examinations, cystic prostatic carcinoma occurs as a large, predominantly cystic mass with wall nodularity. Pathologically, the solid components represent the tumour. ${ }^{5}$

In keeping with other reported MRI findings, the heterogeneous signal intensity of the cystic components and the presence of soft tissue components in our case were suggestive of a neoplastic cause of prostatic cyst. Similar to usual solid prostatic carcinoma, the solid components of the prostatic cystic tumour in our case were noted with restricted diffusion.

In cystic lesions of the prostate, the presence of blood from aspiration should raise suspicion of malignancy, either the cystic mass is malignant or there is associated prostate carcinoma. ${ }^{9}$ These aspirates were reported to contain a high concentration of PSA and $\gamma$-seminoprotein. ${ }^{12}$ To obtain histology and confirm the diagnosis, biopsies should be performed on the solid components of the prostatic cystic tumour to maximise the yield. 
TABLE I. Case reports on cystic prostatic carcinoma

\begin{tabular}{|c|c|c|c|c|c|}
\hline Case & Authors, year & $\begin{array}{c}\text { Age } \\
\text { (years) }\end{array}$ & Presentation & $\begin{array}{c}\text { PSA } \\
\text { (ng/mL) }\end{array}$ & Imaging findings \\
\hline 1 & $\begin{array}{l}\text { Llewellyn et al, } \\
1991^{5}\end{array}$ & 68 & $\begin{array}{l}\text { Bladder outlet } \\
\text { obstruction }\end{array}$ & 32 & $\begin{array}{l}\text { Ultrasonography: } 4.5-\mathrm{cm} \text { cystic mass arising from prostate. Fronds of } \\
\text { solid tissue projected into the cystic component of this mass }\end{array}$ \\
\hline 2 & Parr et al, $1994^{6}$ & 68 & $\begin{array}{l}\text { Constipation, voiding } \\
\text { difficulty }\end{array}$ & 92 & $\begin{array}{l}\text { CT: large heterogeneous cystic mass between prostate and rectum, } \\
\text { while size was not specified }\end{array}$ \\
\hline 3 & Agha et al, $1996^{7}$ & 80 & Epididymorchitis & 272 & $\begin{array}{l}\text { Ultrasonography: } 1.8-\mathrm{cm} \text { cyst with irregular outline in prostate. The } \\
\text { wall of cyst showed multiple footlike processes of solid tissue }\end{array}$ \\
\hline 4 & Tsuji et al, $1999^{2}$ & 68 & Haematuria & $>50$ & $\begin{array}{l}\text { CT: cystic mass measuring } 15 \mathrm{~cm} \text { in diameter in the right posterior } \\
\text { aspect of urinary bladder }\end{array}$ \\
\hline 5 & $\begin{array}{l}\text { Khorsandi et al, } \\
2002^{8}\end{array}$ & 64 & $\begin{array}{l}\text { Abnormal digital rectal } \\
\text { exam }\end{array}$ & 2.9 & СТ: 7-cm cystic mass around prostate and compress rectum \\
\hline 6 & Chang et al, $2005^{9}$ & 66 & $\begin{array}{l}\text { Lower urinary tract } \\
\text { symptoms }\end{array}$ & 33.3 & $\begin{array}{l}\text { MRI: } 6.3-\mathrm{cm} \text { well-defined mass with heterogeneous signals in } \\
\text { rectovesical pouch }\end{array}$ \\
\hline 7 & Chen et al, $2008^{10}$ & 62 & Elevated PSA & 502 & $\begin{array}{l}\text { Transrectal ultrasonography: } 3.9-\mathrm{cm} \text { cystic lesion in prostate. There } \\
\text { was hypoechoic content within the cyst }\end{array}$ \\
\hline 8 & $\mathrm{Ng}$ et al, $2011^{11}$ & 67 & Acute urinary retention & 1324 & MRI: 6-cm intra-prostatic cystic lesion with intralesional haemorrhage \\
\hline 9 & Nerli et al, $2016^{12}$ & 72 & Acute urinary retention & 100 & CT: $6.5-\mathrm{cm}$ cystic lesion in prostate with multiple nodules in the wall \\
\hline 10 & Current case & 81 & Acute urinary retention & 23.8 & СТ: $10-\mathrm{cm}$ hypodense cystic lesion in the rectovesical space \\
\hline
\end{tabular}

Abbreviations: $\mathrm{CT}$ = computed tomography; $\mathrm{MRI}=$ magnetic resonance imaging; PSA = prostate-specific antigen

TABLE 2. Data extracted from 10 case reports on cystic prostatic carcinoma*

\begin{tabular}{lccc}
\hline & Literature review (9 cases) $)^{2,5-12}$ & Present case & All cases (mean) \\
\hline Age (years) & $68.3(62-80)$ & 81 & 69.6 \\
Initial clinical presentation & - LUTS: $33 \%(3$ out of 9$)$ & Urinary retention & \\
& $\begin{array}{l}\text { - Urinary retention: } 22 \%(2 \text { out of } 9) \\
\text { - Abnormal PR exam: } 11 \%(1 \text { out of } 9)\end{array}$ & & \\
& - Epididymorchitis: $11 \%(1$ out of 9$)$ & & \\
& - Haematuria: $11 \%(1$ out of 9$)$ \\
& - Elevated PSA: $11 \%(1$ out of 9$)$ & & 243.2 \\
PSA $(\mathrm{ng} / \mathrm{mL})$ & $267.6(2.9-1324)$ & 23.8 & 6.8 \\
\hline Size of cystic prostatic carcinoma $(\mathrm{cm})$ & $6.4(1.8-15)$ & 10.1 & \\
\hline
\end{tabular}

Abbreviations: LUTS = lower urinary tract symptoms; PR = per rectal; PSA = prostate-specific antigen

* Data are presented as mean (range) unless otherwise indicated

In our case and nine reviewed case reports, all pathological findings of cystic prostatic carcinoma were adenocarcinoma. Of them, one case was reported to have a ductal component. However, the pathogenesis of cystic prostatic carcinoma is not well understood. It has been hypothesised that it is either associated with a pseudocyst due to central necrosis or haemorrhage in the prostatic carcinoma or with malignant degeneration of a retention cyst. ${ }^{9}$ A Japanese study of prostate cancer with cyst formation found that most reported cystic prostatic carcinomas were pseudocysts with haemorrhage; only $17 \%$ were derived from degeneration of a retention cyst. $^{13}$

Tumour staging affects treatment. Among the nine cases reviewed, bone scan was often performed to detect bone metastases. The treatment strategy for cystic prostatic carcinoma includes curative and palliative treatment. The modalities of treatment in this case series were similar to those for classic prostatic carcinoma and included surgery, radiotherapy, and hormonal therapy.

Among the nine cases reviewed, most patients were followed up with PSA level after treatment and a reduced PSA level was noted in all cases. Some cases also had imaging follow-up of the tumour and showed size reduction. Unfortunately, most case reports had no long-term follow-up results available.

In conclusion, malignant prostatic cysts are rare but an important differential diagnosis in prostatic cystic lesion. Prostatic cystic lesion with nodular wall and internal solid components is highly suspicious of cystic prostatic carcinoma. The MRI features of cystic prostatic carcinoma include evidence of haemorrhage, heterogeneous signal intensity of the cystic component, and presence of 
soft tissue elements. Image-guided biopsy targeting the solid component is suggested to obtain a histological diagnosis.

\section{Author contributions}

All authors had full access to the data, contributed to the study, approved the final version for publication, and take responsibility for its accuracy and integrity.

Concept or design: KH Fung, WK Tsang, PCH Kwok. Acquisition of data: KH Fung, WK Tsang, PCH Kwok, WT Lee.

Analysis or interpretation of data: KH Fung, WK Tsang, WT Lee.

Drafting of the article: KH Fung, WK Tsang, WT Lee.

Critical revision for important intellectual content: All authors.

\section{Conflicts of interest}

The authors have no conflicts of interest to disclose.

\section{Funding/support}

This case report received no specific grant from any funding agency in the public, commercial, or not-for-profit sectors.

\section{Ethics approval}

The patient was treated in accordance with the Declaration of Helsinki. The patient provided informed consent for all procedures.

\section{References}

1. Lim DJ, Hayden RT, Murad T, Nemcek AA Jr, Dalton DP.
Multilocular prostatic cystadenoma presenting as a large complex pelvic cystic mass. J Urol 1993;149:856-9.

2. Tsuji H, Hashimoto K, Katoh Y, Iguchi M. Prostatic cancer with huge cystic degeneration. Urol Int 1999;62:48-50.

3. Hamper UM, Epstein JI, Sheth S, Walsh PC, Sanders RC. Cystic lesions of the prostate gland. A sonographicpathologic correlation. J Ultrasound Med 1990;9:395-402.

4. Curran S, Akin O, Agildere AM, Zhang J, Hricak H, Rademaker J. Endorectal MRI of prostatic and periprostatic cystic lesions and their mimics. AJR Am J Roentgenol 2007;188:1373-9.

5. Llewellyn $\mathrm{CH}$, Holthaus LH. Cystic carcinoma of the prostate: findings on transrectal sonography. AJR Am J Roentgenol 1991;157:785-6.

6. Parr NJ, Hawkyard SJ. Carcinoma of the prostate presenting as cystic pelvic mass. Br J Urol 1994;73:213-4.

7. Agha AH, Bane BL, Culkin DJ. Cystic carcinoma of the prostate. J Ultrasound Med 1996;15:75-7.

8. Khorsandi M. Cystic prostatic carcinoma. J Urol 2002;168:2542.

9. Chang YH, Chuang CK, Ng KF, Liao SK. Coexistence of a hemorrhagic cyst and carcinoma in the prostate gland. Chang Gung Med J 2005;28:264-7.

10. Chen $\mathrm{CH}$, Lin YH, Tzai TS, Tsai YS. Prostate cancer associated with hemorrhagic cyst: findings on transrectal Doppler sonography. J Med Ultrasound 2008;16:292-5.

11. Ng KL, Sathiyananthan JR, Dublin N, Razack AH, Lee G. Cystic adenocarcinoma of prostate: a case report. J Health Transl Med 2011;14:21-2.

12. Nerli RB, Patil R, Sharma V, Ghagane SC, Hiremath MB. Cystic prostatic carcinoma. Clin Oncol 2016;1:1154.

13. Kim SC, Fujimoto K, Matsumoto Y, et al. A case of prostate cancer with cyst formation [in Japanese]. Hinyokika Kiyo 2001;47:653-6. 